\title{
Article \\ A High Temperature Solid Pressure Sensor Based on Fiber Bragg Grating
}

\author{
Hongying Guo ${ }^{1, *} \mathbb{( D}$, Jiang Chen ${ }^{2}$, Zhumei Tian ${ }^{1} \mathbb{D}$ and Aizhen Wang ${ }^{1}$ \\ 1 Department of Electronics, Xinzhou Teachers University, Xinzhou 034000, China; xiaotia0121@sina.com (Z.T.); \\ waz7637@163.com (A.W.) \\ 2 MOE Key Laboratory of Deep Earth Science and Engineering, Sichuan University, Chengdu 610017, China; \\ chxifei@scu.edu.cn \\ * Correspondence: ggghy91832021@163.com; Tel.: +86-186-3604-2975
}

check for updates

Citation: Guo, H.; Chen, J.; Tian, Z.; Wang, A. A High Temperature Solid Pressure Sensor Based on Fiber Bragg Grating. Symmetry 2021, 13, 2098. https://doi.org/10.3390/sym13112098

Academic Editors:

Christophe Humbert and Boris Malomed

Received: 13 September 2021

Accepted: 22 October 2021

Published: 5 November 2021

Publisher's Note: MDPI stays neutral with regard to jurisdictional claims in published maps and institutional affiliations.

Copyright: (c) 2021 by the authors. Licensee MDPI, Basel, Switzerland. This article is an open access article distributed under the terms and conditions of the Creative Commons Attribution (CC BY) license (https:/ / creativecommons.org/licenses/by/ $4.0 /)$.

\begin{abstract}
For the requirement of pressure detection in high temperature environments, this paper presents a fiber Bragg grating (FBG) based pressure sensor with a simple structure. The structural model of the sensor has been established with the consideration of a sensing principle and a small deflection effect of the circular membrane. The finite element analysis has been employed to validate the rationality of the sensor structure design and realize the digital simulation of the theoretical model. Through the analysis, the selection of packaging materials, the design of structural parameters and the pressure and temperature calibration of the developed sensor has been performed. The encapsulation of the sensor at high temperatures has been improved based on the theoretical analysis, simulation and testing, which proves the effectiveness of the sensor for pressure measurement at high temperatures of $100{ }^{\circ} \mathrm{C} 250^{\circ} \mathrm{C}$. The study provides a feasible sensing device for high-temperature pressure detection.
\end{abstract}

Keywords: FBG; pressure detection; simulation analysis; high temperature encapsulation; temperature compensation

\section{Introduction}

When the ammunition is stimulated by heat, the pressure in the ammunition body will increase sharply due to the influence of temperature change, which may lead to accidental explosion of the ammunition body, thus causing serious loss of life and property and a negative social impact. It is very important to detect the thermal stability of ammunition and evaluate the security and environmental adaptability of the ammunition system. In order to test the thermal stability of ammunition, a heat sensitivity burning experiment is usually carried out on live ammunition to understand the intensity of the reaction of the energy material in the ammunition. The temperature and pressure in the projectile are the important parameters to reflect the thermal stability of the ammunition in the process of the projectile being heated, so the temperature and pressure detection in the projectile is an important part of the ammunition detection system.

The schematic diagram of ammunition thermal safety detection is shown in Figure 1. Due to the particularity of the measured medium and the strong coupling of various physical sites, such as field, temperature field and vibration field, common electrical, ultrasonic and electromagnetic pressure sensing detection technologies, cannot effectively meet the requirements of pressure detection. For the detection of solid pressure, Fiber Bragg grating (FBG) pressure sensing technologies can overcome the disadvantages of conventional pressure sensors such as poor stability, poor moisture resistance, and susceptibility to electromagnetic interference in harsh environments; at the same time, the grating sensor is a passive device, which does not need on-site power supplies. As an important basis to reflect the working state, fault diagnosis and the evaluation of complex detection systems, solid internal pressure has always been the key parameter of various 
detection systems [1]. Compared with the traditional electrical or electromagnetic pressure sensors, Fiber Bragg grating (FBG) pressure sensors have unique advantages in sensing medium and signal transmissions, such as corrosion resistance, safety and explosion-proof, signal confidentiality, anti-electromagnetic interference, long signal-transmission distance, strong multiplexing ability, and so forth [2-4]. In particular, the advantages of long transmission distance make the signal-gratings available to be arranged in different positions of the fiber, which provides convenient conditions for the realization of the multi-point quasi-distributed detection of the internal pressure for the detection system, and has broad application prospects in monitoring and fault diagnosis fields of system conditions [5-7]. The use of fiber grating pressure sensing technologies for solid pressure detections can overcome the shortcomings of poor stability, poor moisture-proof performance as well as vulnerability to electromagnetic interference in harsh environments. At the same time, the grating sensor is a passive device, which does not need on-site power supply, which has unique advantages for long-term distributed monitoring (especially in the harsh, flammable and explosive detection environment, electromagnetic interference and strong radiation), and which is increasingly used in solid pressure detections [8,9].

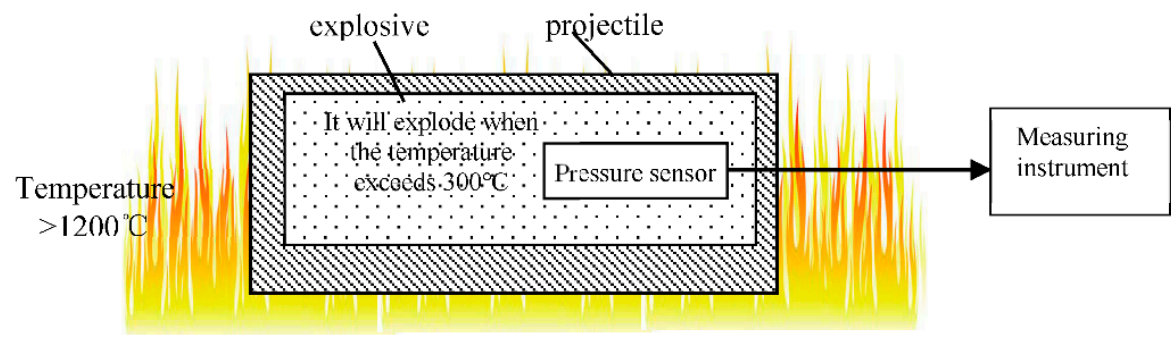

Figure 1. Schematic diagram of pressure test under high temperature.

In 2005, Sun, A. [10] proposed a practical method for the measurement of pressure and temperature using a dual FBG gas sensor, in which the dual FBG is coated in a specific metal tube through a special polymer. The temperature and pressure errors of the sensors are approximately $0.5^{\circ} \mathrm{C}$ and $0.5 \mathrm{MPa}$, respectively, in the measuring ranges of 20 to $100{ }^{\circ} \mathrm{C}$ and 0 to $20 \mathrm{MPa}$. In 2008, Ahmad, H. [11] applied polymer as encapsulation material to design grating pressure sensor. During encapsulation, the polymer was introduced into the mold which was pre-placed into the grating, and the encapsulation was completed after the polymer was cured. The pressure sensitivity of the sensor reached $8.76 \times 10^{-3} \mathrm{~nm} / \mathrm{Pa}$.

In 2009, Zou, J. L. [12] designed a grating pressure sensor by connecting a section of metal threaded tube to the middle part of the metal tube and adhered both ends of the fiber grating to the wall of the threaded tube. The sensitivity of the sensor reached $4.8 \times 10^{-2} \mathrm{~nm} / \mathrm{Pa}$, but the dynamic range of the sensor was small and it could only be used for low-voltage detection. In 2012, Xiong, Y. [13] designed a FBG solid pressure sensor with a flat diaphragm structure. Based on the mechanical model of the planar diaphragm, by using ANSYS finite element analysis software, the structure and parameters of the sensor are simulated and optimized. The flat diaphragm structure is more suitable for sensors with large range. In 2013, Li [14] proposed the fiber Bragg grating soil pressure sensor based on double L-shaped levers. The sensor can effectively transform the deformation of the diaphragm under soil pressure into the longitudinal strain of the fiber grating by thr structure of a double L-shaped lever. The sensitivity of the sensor is theoretically analyzed and verified by experiments. The sensor has been calibrated in the laboratory. The experimental results Conformed to the theoretical expectation. Huang J and Zhou, Z. [15] proposed and studied a diaphragm pressure sensor with two FBGs. The FBG was directly bonded to the circular diaphragm along the radial direction, and the positive strain and negative strain were measured respectively by using the wavelength offset difference of the two FBGs as the sensing signal, which increased the pressure sensitivity and compensated the temperature cross sensitivity. 
In 2015, Pachava, V. R. [16] designed a high-sensitivity solid pressure sensor using fiber Bragg grating and carried out theoretical and experimental studies. The deflection of the diaphragm causes tensile strain in the axial direction of the FBG. From the test results, the sensitivity of the pressure sensor is $2.05 \times 10^{-2} \mathrm{~nm} / \mathrm{MPa}$. The experimental results agree well with the theoretical design. In 2015, Pachava, V. R. [17] putted forward a piston fiber Bragg grating pressure sensor by using a metal spring as a sensing element. The sensitivity of the sensor reached $0.57 \times 10^{-3} \mathrm{~nm} / \mathrm{Pa}$, and both linearity and repeatability were good. In the same year, the same laboratory [18] designed and developed another fiber Bragg grating pressure sensor, which used bellows as the pressure sensing element and increased the pressure sensitivity of the bare fiber grating by 4000 times to $90.6 \mathrm{PM} / \mathrm{psi}$. Allwood, G. [19] describes a new type of highly sensitive diaphragm-based solid pressure sensor. They designed the physical structure, analyzed an in-depth of the optical response to pressure changes, and discussed the experimental calibration and its limitations. The results show that the sensitivity of the sensor is $0.116 \mathrm{~nm} / \mathrm{kPa}$ in the range of $15 \mathrm{kPa}$. In 2016, scholar Rodriguez [20] carried out an experiment based on LANL thermal safety detection, in which a grating (FBG) was embedded into a bomb to test the pressure in the bomb after PBXN-9 explosive was ignited. Finally, the judgment of response level was obtained through this experiment. Li, T. L. [21] developed a fiber Bragg grating (FBG) vibration sensor with double differential temperature compensation. To achieve double differential temperature compensation, two FBGs and two states of the sensor have been employed in it. In 2018, Liang, P. [22] designed and fabricated a fiber Bragg grating liquid pressure sensor by pasting a grating on the elastic diaphragm. The dynamic range of the sensor was $0 \sim 104 \mathrm{~Pa}$, and the sensitivity was $0.15 \times 10^{-2} \mathrm{~nm} / \mathrm{Pa}$. In 2019, Shen, J. H. [23] proposed a method of embedding optical fiber into smart FRP bars and carried out relevant research. The method uses common single-mode fiber as distributed sensor. In 2021, Wang, et al. [24] developed CFRP composite plates assembled with fiber Bragg grating (FBG) sensors for the dynamic response identification of CFRP plate. In the same year, Wang, et al. [25] studied the improved temperature-compensation measures for FBG based sensors under different loading conditions (high and low temperature, static and dynamic mechanical load), with the temperature hysteresis of FBG sensing elements considered.

For this detection environment, the pressure measuring range of the above sensors is generally low, and the applicable range of the ambient temperature is small, so it cannot be used for the pressure detection in the projectile. In this paper, the grating and packaging technology that can adapt to the detection environment in the projectile will be selected to carry out the research on the detection method of pressure in the projectile under the condition of the projectile body being heated. On the basis of studying the detection principle and implementation technology of each parameter in the missile detection system, a new fiber grating pressure sensor is developed according to the environmental characteristics of the missile detection system. Through in-depth research on the influence of high temperature environment on the detection signal of FBG, the influence of configuration deformation on the output characteristics of FBG and its correlation, the optimal matching parameters of configuration and grating are determined, which provides theoretical support for the design of high-performance sensor prototype.

The author has made some preliminary explorations in this field, such as designing a grating pressure sensor that can realize high pressure detection at room temperature [26], and simulating the influence of sensor model deformation on pressure detection in high temperature environment [27]. To conform to detection requirements, in this paper, the sealing structure of sensor was improved, proper high temperature-resistant grating was selected, relevant parameters of the sensor's structure were designed, and the non-linear model for temperature response was also revised. Experiments have been conducted, such as pressure calibration, temperature calibration and the pressure calibration at different temperatures, to test the devised sensor. In all those experiments, the temperature compensation effect was in line with expectations, and the validity of the sensor measuring pressure at high temperatures was also validated. 


\section{Fiber Bragg Grating Sensing Principle}

Fiber Bragg grating (FBG) is a kind of optical fiber core placed in the interference fringe of strong light, through a certain time of irradiation to form periodic refractive index changes along the axial component of the fiber. This change will affect the propagation direction of a small part of the spectrum. Therefore, when the broadband light wave enters the fiber and reaches the grating, a small part of the broadband light wave will be reflected at the original wavelength and return to the incident end, while the rest of the light will be transmitted at the grating, unaffected and continue to transmit along the fiber. In this way, the fiber Bragg grating can have the function of filtering the light wave. Reflects the output wavelength characteristics of grating, and is commonly used to study the basic relationship of grating sensing:

$$
\lambda_{B}=2 n_{e f f} \Lambda
$$

In Formula (1), $n_{\text {eff }}$ is the effective refractive index of grating. $\Lambda$ is the grating period. When grating is fabricated, the grating period can be modulated by changing the Angle between two coherent beams. In this way, Bragg gratings with different central reflection wavelengths can be fabricated. It can be seen from Formula (1) that the effective refractive index and grating period of FBG are the factors affecting the change of FBG center wavelength. Any method to change these two parameters can cause wavelength shift of FBG. Only strain and temperature, two key parameters, are the direct factors that can cause the wavelength shift of Bragg grating. The influence of refractive index distribution at the Fiber Bragg Grating on the optical signal entering the fiber is shown in Figure 2.

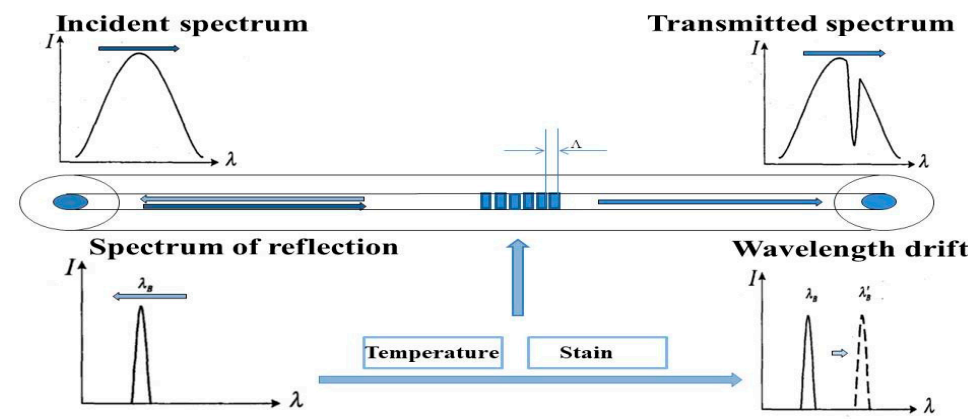

Figure 2. Schematic diagram of the basic principles about fiber grating sensing [28].

When the ambient temperature of the grating increases, the period of the grating will change under the action of thermal expansion. At the same time, the effective refractive index of the grating will change due to the thermal sensitivity effect, which makes the central wavelength of the grating shift. When the temperature range is small, the relationship between the offset of the center wavelength of the grating and the temperature change is:

$$
\Delta \lambda=\mathrm{K}_{T} \Delta T \text {. }
$$

When the temperature range is large, the relationship become $[29,30]$ :

$$
\Delta \lambda=A \Delta T^{2}+B \Delta T+C
$$

Similarly, when the Bragg grating is compressed or stretched by the external force, the period of the grating will change significantly. In addition, due to the elasto-optical effect of the grating, the effective refractive index of the grating will also change with the elastic deformation of the grating, resulting in the shift of the central wavelength of the grating. The relationship between the offset of grating center wavelength and the change of strain is:

$$
\Delta \lambda_{B}=K_{\varepsilon} \varepsilon
$$


Therefore, in order to realize the sensing detection of temperature and strain, the change information of temperature and strain can be obtained by detecting the change of FBG reflection center wavelength. Only temperature and strain can be directly detected by the grating. For other parameters (such as pressure, speed, displacement etc.), the sensor needs to be encapsulated, and the changes of the parameters to be detected are converted into the strain of the grating through different packaging structures to realize signal detection. In addition, the sensor package can also play a role in mechanically protecting the FBG, increasing detection sensitivity, and realizing temperature compensation.

\section{Sensor Design}

According to the characteristics of the projectile body detection environment, combined with the investigation of the projectile body's material, structure, thickness and other parameters, the following requirements are put forward for the projectile body pressure sensor's use environment and measuring range: (1) the detection temperature is not less than $300{ }^{\circ} \mathrm{C}$; (2) The pressure measurement range is 0 50 $\mathrm{MPa}$. In the sensor design, the physical properties of packaging materials, such as: elastic modulus, Poisson's ratio; The shape parameters of the sensor package structure, such as sensor diameter, diaphragm thickness and so on, are one of the direct factors affecting the sensor range and sensitivity. The selection of appropriate packaging materials and reasonable sensor structure are important factors for achieving the sensor design goal. This section will optimize the material and optimize the packaging structure form and parameters.

\subsection{Design of the Conversion Mechanism between Pressure and Grating Strain}

According to the relevant research results of solid mechanics, solid pressure sensor matching error and engineering practice, the sensor is designed into a circular pie shape that can obtain a relatively ideal detection value, so the appearance of the FBG pressure sensor is designed into a circular pie shape cylindrical model. The package structure of the sensor should be able to convert the external pressure into the strain of the FBG, that is, the external pressure is converted into the stretching or compression of the grating. In order to achieve this goal, two fixed columns are arranged symmetrically and vertically inside the pressure diaphragm of the sensor to fix the two ends of the grating. When pressure is applied to the diaphragm, it will cause a downward micro-deformation of the diaphragm. This deformation will drive the two fixed columns to produce deformation in opposite directions, which will pull the grating to produce strain on the grating. In order to further verify the rationality and effectiveness of the sensor packaging structure design, ANSYS finite element simulation was carried out on the structure model. The straight line, where the fixed column is located is taken as the $X$ direction, the direction perpendicular to $X$ on the pressure diaphragm plane is taken as the $Y$ direction, and the normal direction of the pressure diaphragm plane is taken as the $Z$ direction (upward is positive) to establish the coordinate system, as shown in Figure 3.

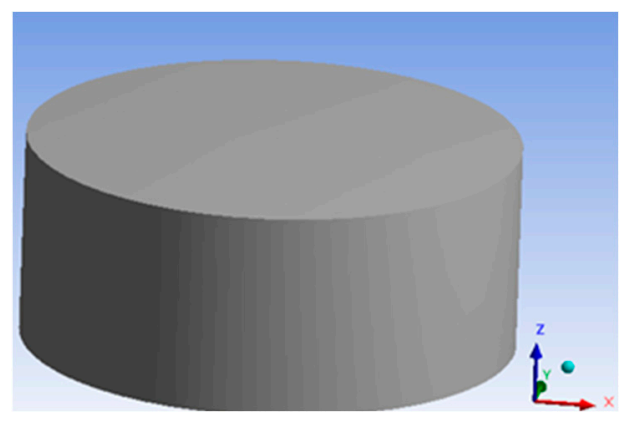

Figure 3. The contour map of sensor model.

The main purpose of this simulation is to verify the rationality of the structure, so no special setting is made for the model material. Instead, $50 \mathrm{MPa}$ pressure load is 
applied to all the outer surfaces of the model with the default structural steel setting of the ANSYS system, and the displacement distribution of the deformation generated inside the packaging model in the three directions of $X, Y, Z$ is shown in Figures 4-6.

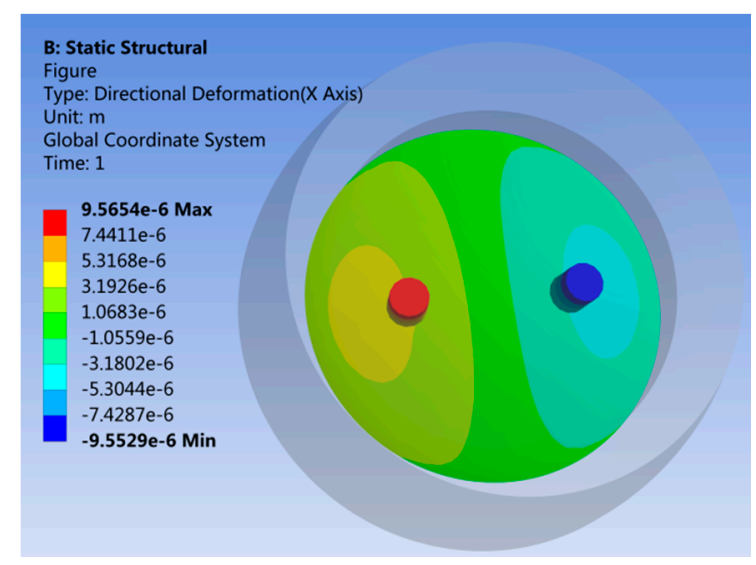

Figure 4. The internal deformation distribution of $X$ direction.

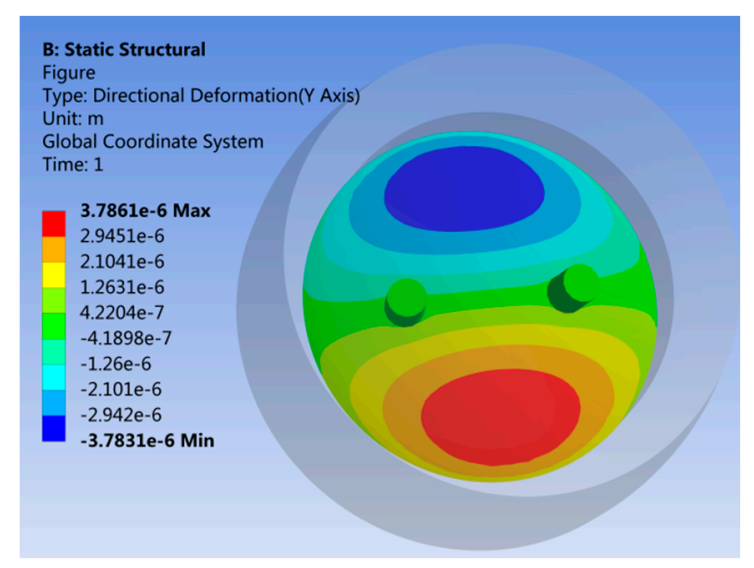

Figure 5. The internal deformation distribution of $Y$ direction.

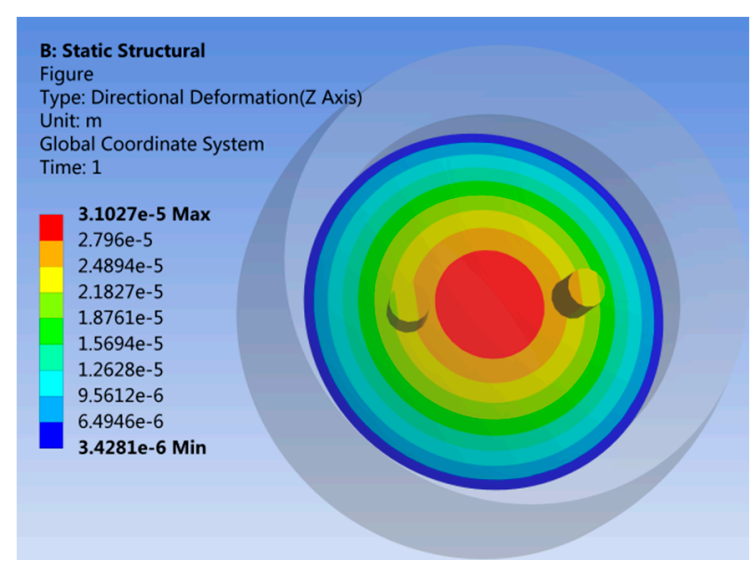

Figure 6. The internal deformation distribution of $Z$ direction.

Figures 4-6 show the deformation cloud diagram inside the model when $50 \mathrm{MPa}$ pressure is applied to the model. Figures 4 and 5 show the deformation distribution of each point inside the structure in $X$ and $Y$ directions, respectively. Figure 6 shows the deformation distribution of each point inside the structure in the $Z$ axis direction. As can be seen from Figure 4, the deformation of the two fixed columns in the $X$ direction is 
the largest and the size is close to the opposite direction. However, as can be seen from Figure 5, the deformation of the two fixed columns in the $Y$ direction is of the same color, that is, there is little difference in deformation. In Figure 6, the deformation colors in the $Z$ direction are symmetrically distributed with the center of the circle as the center. As long as the fixed column is symmetrically set with the center of the circle as the center, the center points of the two fixed columns have the same color, that is, there is no relative deformation. The straight line where the two fixed columns are taken as the path, and the deformation of the center positions of the two fixed columns in $X, Y$ and $Z$ directions is extracted, as shown in Table 1.

Table 1. Comparison of deformation data after compression.

\begin{tabular}{cccc}
\hline Direction & $\begin{array}{c}\text { Left Fixed Column } \\
(\mu \mathrm{m})\end{array}$ & $\begin{array}{c}\text { Right Fixed Column } \\
(\boldsymbol{\mu m})\end{array}$ & $\begin{array}{c}\text { Relative Elongation } \\
(\boldsymbol{\mu m})\end{array}$ \\
\hline$X$ & -9.54 & 9.56 & 19.10 \\
$Y$ & 0.05 & -0.04 & -0.09 \\
$Z$ & 23.78 & 23.87 & 0.09 \\
\hline
\end{tabular}

From Table 1, we can see clearly that internal model between two fixed column deformation is concentrated in the $X$ direction. The deformation of $Y$ and $Z$ direction is less than one percent of the $X$ direction deformation. If the grating fixed in the center of the two fixed columns, deformation can be concentrated in the $X$ direction, without the influence of $Y$ and $Z$ direction. Therefore, this structure can convert the pressure perpendicular to the outer surface of the sensor into the stretching of the grating. It is worth mentioning that the deformation of the grating is concentrated in the radial direction of the fiber, effectively eliminating the radial deformation. Moreover, it can be seen from Figure 4 that the deformation of the two fixed columns is the largest and the direction is opposite. The grating is set between the two fixed columns to obtain greater pressure sensitivity. Therefore, the design of sensor packaging structure is reasonable.

\subsection{Selection of Packaging Materials}

On the basis of ensuring the range of the sensor, the detection sensitivity of the sensor should be increased as far as possible when selecting the material. The performance parameters, such as elastic modulus, Poisson's ratio and coefficient of thermal expansion of the packaging material, are all factors that affect the detection accuracy of the sensor. Before the packaging experiment, different performance parameters were set according to the characteristics of common metals. The finite element method was used to calculate the deformation results of the sensor model under each material setting. The appropriate packaging materials were selected according to the specific requirements of the testing environment.

By comparing the parameters of several common metals in Table 2, it can be seen that the parameters of different materials vary greatly. The elastic modulus and Poisson's ratio are the main parameters that affect the deformation of the model. By selecting different material parameters and applying $50 \mathrm{MPa}$ pressure to the designed model, it can be seen that the deformation trend of all materials is basically the same, but the deformation data are greatly different. Select steel as the packaging material. Both structural steel and stainless steel can be used for sensor packaging. For different types of steel, the material parameters are also greatly different, in order to ensure that the sensor to obtain greater pressure sensitivity, and light weight, less affected by temperature, try to choose the density, elastic modulus, thermal expansion coefficient of steel are relatively small, more suitable for sensor packaging. Through the comparison of various steel parameters, 304 stainless steel is selected as the packaging material of the sensor. 
Table 2. Material parameters of common metals.

\begin{tabular}{|c|c|c|c|c|c|c|}
\hline Metal & Copper & Structural Steel & Cast Iron & Aluminum Alloy & Aluminum & Stainless Steel \\
\hline $\begin{array}{l}\text { Density } \\
\left(\mathrm{g} / \mathrm{cm}^{3}\right)\end{array}$ & 8.96 & 7.85 & 7.3 & 2.82 & 2.69 & 7.93 \\
\hline Elastic Modulus (GPa) & 106 & 210 & 100 & 70 & 71.7 & 190 \\
\hline $\begin{array}{l}\text { Coefficient of thermal } \\
\text { expansion } 1 \times 10^{-6} /{ }^{\circ} \mathrm{C} \text { ) }\end{array}$ & 20.8 & 12 & 11.8 & 23.6 & 23.2 & 16 \\
\hline $\begin{array}{l}\text { Thermal conductivity } \\
(\mathrm{w} / \mathrm{m} \cdot \mathrm{k})\end{array}$ & 383 & 60.5 & 39.2 & 209 & 204 & 17 \\
\hline Poisson's ratio & 0.324 & 0.3 & 0.211 & 0.33 & 0.33 & 0.3 \\
\hline
\end{tabular}

\subsection{Fiber Coating Selection}

The coating material of ordinary grating is acrylic resin. The stability of the grating was improved by coating the fiber with acrylic resin and UV curing. The operating temperature range of acrylic coating is $-20^{\circ} \mathrm{C} \sim 85^{\circ} \mathrm{C}$, which obviously cannot meet the purpose of high temperature pressure sensing in this paper. Although the high temperature resistant acrylic resin coating has been developed, its high temperature resistance is up to $150{ }^{\circ} \mathrm{C}$, which obviously cannot meet the goal of realizing pressure sensing under high temperature in this paper.

Heat resistant silicone, acrylic resin, polyimide and metal coating are currently the most widely used coating materials for optical fibers [26]. Different coating materials result in different temperature resistance characteristics of optical fibers. Table 3 shows the specific performance comparison of optical fibers coated with different coating materials [31]:

Table 3. Comparison of physical properties of fibers coated by different materials.

\begin{tabular}{cccc}
\hline Coating Material & Electrical Conductivity & $\begin{array}{c}\text { Maximum Operating Temperature } \\
\left({ }^{\circ} \mathbf{C}\right)\end{array}$ & $\begin{array}{c}\text { Modulus of Elasticity } \\
\text { (Gpa) }\end{array}$ \\
\hline polyimide & High insulating material & 350 & $3-4 \mathrm{Gpa}$ \\
Acrylic resin & General insulating material & $80 \sim 120$ & $1 \mathrm{Gpa}$ \\
Heat resistant silicone & General insulating material & 280 & $1.2 \mathrm{Gpa}$ \\
Metal coating & conductive & $\mathrm{Al} \mathrm{400} \mathrm{Cu} \mathrm{600} \mathrm{Au} \mathrm{700}$ & $100-130 \mathrm{Gpa}$ \\
\hline
\end{tabular}

The fiber coated with heat-resistant silica gel and acrylic resin can be used in a small temperature range. As the coating layer of optical fiber, metal material can work under a high temperature environment, but the fabrication of grating on such optical fiber requires quite complex process, and the optical power will also suffer a large loss in the transmission process. Polyimide as the coating high temperature resistant grating, high temperature environment performance is good, the production process is mature. The high temperature resistance range of the coated polyimide grating can be between $200{ }^{\circ} \mathrm{C}$ and $350{ }^{\circ} \mathrm{C}$, especially the specially treated polyimide grating can withstand the high temperature of $400{ }^{\circ} \mathrm{C}$ or even above. In terms of mechanical properties, the polyimide fiber itself has a strong ability, and its tensile strength is greater than $100 \mathrm{MPa}$. Therefore, considering the above characteristics, this design selects polyimide as the coating layer of optical fiber to fabricate the grating. The parameters of polyimide fiber are shown in Table 4: 
Table 4. Polyimide fiber parameter list.

\begin{tabular}{ccc}
\hline Parameter & Unit & Parameter Content \\
\hline the core material & - & quartz \\
Coating material & - & polyimide \\
Numerical aperture & - & 0.5 \\
Core index of refraction & - & 1.49 \\
Cladding index of refraction & - & 1.404 \\
Refractive index distribution & - & Step refractive index \\
The fiber core diameter & $\mu \mathrm{m}$ & 125 \\
The cladding diameter & $\mu \mathrm{m}$ & $155 \pm 5$ \\
Working temperature & ${ }^{\circ} \mathrm{C}$ & $-65 \sim+300$ \\
Transmission loss & $\mathrm{dB} / \mathrm{km}$ & 150 \\
Minimum bending radius & $\mathrm{Mm}$ & 25 \\
\hline
\end{tabular}

\subsection{Glue Selection}

Glue selection should consider both the highest temperature glue that can be used, but also consider its mechanical properties. Based on the above two factors, high temperature resistant sealant HBC-1096 is selected. Its related performance indicators are shown in Table 5:

Table 5. High temperature resistant sealant HBC-1096 performance indicators.

\begin{tabular}{cc}
\hline Parameter & Parameter Content \\
\hline Service temperature range $\left({ }^{\circ} \mathrm{C}\right)$ & $-80 \sim+1300$ \\
Complete curing time $\left(\mathrm{d}, 25^{\circ} \mathrm{C}\right)$ & $3 \sim 7$ \\
Tensile strength $(\mathrm{MPa})$ & 1.5 \\
Shear strength $(\mathrm{MPa})$ & 2.0 \\
Peel strength $(\mathrm{N} / \mathrm{mm})$ & 7 \\
Linear shrinkage $(\%)$ & 0.5 \\
\hline
\end{tabular}

\subsection{Parameter Design}

The structure of the FBG solid pressure sensor designed in this paper is composed of two parts: the pressure diaphragm, the sensor shell and the stainless steel top cover. The substrate materials used for the two parts are the same. The pressure diaphragm is composed of a circular elastic diaphragm and a solid pressure grating fixed column. The fixed column and the elastic diaphragm and the sensor housing are fabricated in one piece to reduce stress concentration or uneven stress. The sensor housing is threaded to the stainless steel top cover. The sensor shell adopts a pressure diaphragm as the elastic element of the sensor to sense the external pressure. Two symmetrical fixed columns are arranged on the pressure diaphragm to fix both ends of the solid pressure sensing grating FBG1. The solid pressure is converted into the strain measured by the FBG through the circular elastic diaphragm. The specific structure is shown in Figure 7.

In Figure 7, two gratings are arranged inside the sensor. FBG1 is pressure-sensitive grating, and both sides of the pressure-sensitive grating are glued to two fixed columns, respectively, for measuring the change of external pressure. Both external pressure and temperature change will affect the pressure-sensitive grating FBG1. The other grating, FBG2, is a temperature complementary grating, which is arranged inside the sensor and has a free end. The deformation of the sensor package structure does not affect it, and its output is only affected by temperature, which is used to measure the temperature around the sensor. The two gratings are arranged inside the sensor and can be considered to be in the same temperature field. The stress analysis and pressure sensitivity of the sensors are carried out for pressure sensitive grating FBG1. 


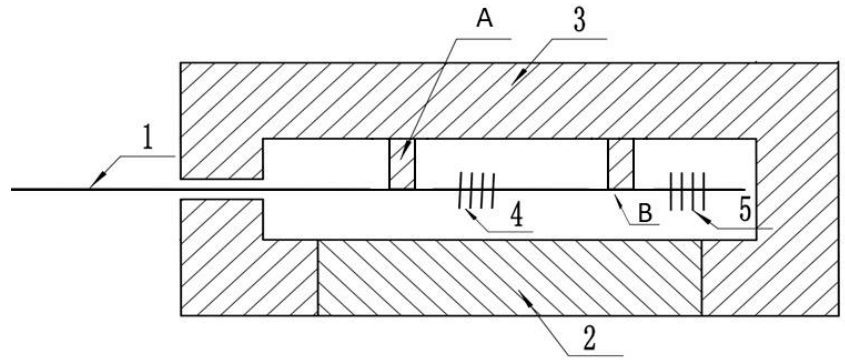

(a)

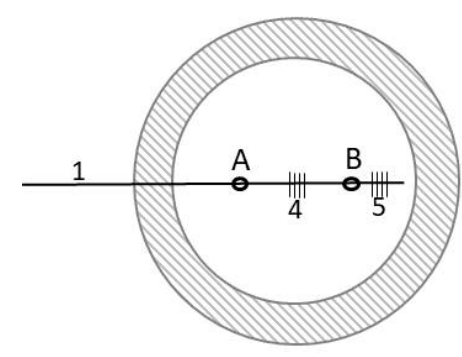

(b)

Figure 7. The internal structure view of the sensor: (a) Cross-sectional view; (b) top view. (1) Optical fiber; (2) Stainless steel cover; (3) Pressure-bearing diaphragm; (4) Pressure-sensitive grating FBG1; (5) Temperature compensated grating FBG2; (A,B). Fixed column.

(1) Thickness design of compressed diaphragm.

The force situation of the sensor conforms to the small deflection bending problem of thin plate in elastic mechanics. According to the relevant differential equation of elastic mechanics, it can be known that:

$$
D\left(\frac{d^{2}}{d \rho^{2}}+\frac{1}{\rho} \frac{d}{d \rho}\right)\left(\frac{d^{2} \omega}{d \rho^{2}}+\frac{d \omega}{d \rho}\right)=P .
$$

In Equation (5), $D$ is the bending stiffness of the diaphragm under pressure, $P$ is the load on the diaphragm, $\omega$ is the center deflection of the diaphragm, $\rho$ is the distance between any point on the diaphragm and the center, $E$ and $\mu$ are the elastic modulus and Poisson's ratio of the diaphragm material; $R$ is the model radius; $h$ is the thickness of the diaphragm, and the distance between the fixed columns is $L$. Solving the above equation, then the conclusion is obtained by using the relevant boundary conditions.

$$
\omega_{\max }=\frac{3 P R^{4}\left(1-\mu^{2}\right)}{16 E h^{3}} .
$$

In order to ensure that the sensor works normally in a small deflection range, $\omega \leq \frac{h}{80}$ should be ensured. The elastic modulus $E$ is $194.02 \mathrm{GPa}$, the Poisson's ratio $\mu$ is 0.28 , and the detection range of the sensor is $50 \mathrm{MPa}$.

According to previous experience, when the radius of the sensor is $120 \mathrm{~mm}$, the detection error is much smaller. Substituting $R=120 \mathrm{~mm}$ into the above equation, it can be measured that the thickness of the pressure diaphragm is $15 \mathrm{~mm}$.

(2) The determination of the distance between optical fiber fixed columns:

The software of ANSYS is applied to exert a pressure of $50 \mathrm{MP}$ on the cavity model. An $X$-axis direction deformation cloud diagram depicting the inside of the compression diaphragm is shown in Figure 7. It shows that the largest deformation of the diaphragm (red and blue) occurs on the $X$-axis. On the inner plane of the diaphragm, the straight line where the $X$-axis is located is taken for path simulation, and the deformation data of points on the path are read for drawing a curve, as is shown in Figure 8.

As is seen from Figure 9, the maximum pressure detection sensitivity can be obtained by placing the fixed column at the position of maximum deformation and fixing the two ends of the grating on the fixed column. The point of maximum deformation is $30 \mathrm{~cm}$ away from the boundary. The distance between the two fixed columns is $60 \mathrm{~cm}$. 


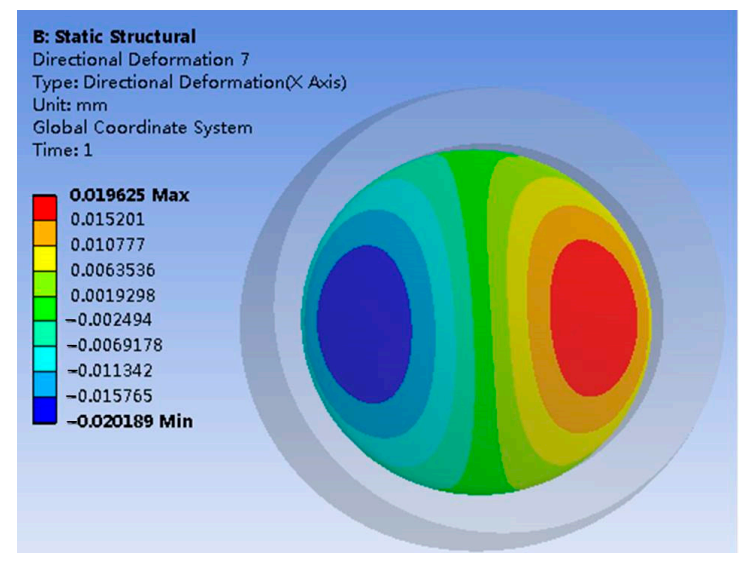

Figure 8. Internal deformation view of the model under compression.

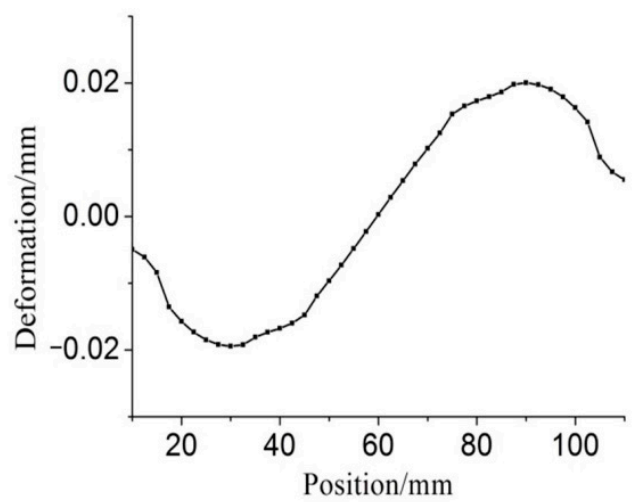

Figure 9. Path deformation diagram.

However, if the distance between the fixed columns is too large, the strain distribution on the grating will be uneven, which will affect the pressure detection accuracy of the sensor in the temperature changing environment. By carefully observing the locationdeformation curve, it can be found that the curve is near the peak value and the collected data points are dense. Since the data collection points collect deformation data at equal intervals, the slope of change between the position near the peak value and the deformation data becomes smaller. In order to comprehensively consider the purpose of increasing the pressure sensitivity of the sensor and reducing the temperature sensitivity of the grating, the intersection point of the line with the highest slope of the position-deformation curve and the curve was used as the placing point of the fixed column. It can be seen that the two fixed columns are $40 \mathrm{~mm}$ apart and symmetric about the origin. It is shown in Figure 10.

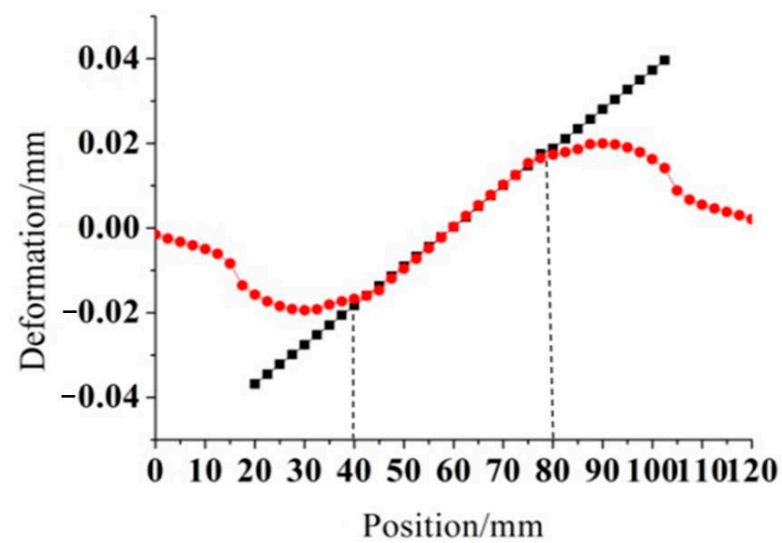

Figure 10. Selection of fixed column position. 
(3) The design of fixed column height and sensor height.

The height design of the fixed column is based on the principle of convenient grating placement and installation. The height of the fixed column is designed as $m=10 \mathrm{~mm}$. Sensor by diaphragm thickness, fixed the height of the column height, the distance between the fixed column and shell, by the design of the front, the diaphragm thickness of $h=$ $15 \mathrm{~mm}$, fixed column height $m=10 \mathrm{~mm}$, in order to convenient encapsulation, avoid grating sensor shell and touch, the design of fixed to $10 \mathrm{~mm}$, the distance between the top of the column and the shell, so the thickness of the sensor is $50 \mathrm{~mm}$.

(4) Pressure sensitivity of the sensor.

When the sensor model is subjected to pressure, the simplified diagram of the pressure diaphragm is shown in Figure 11.

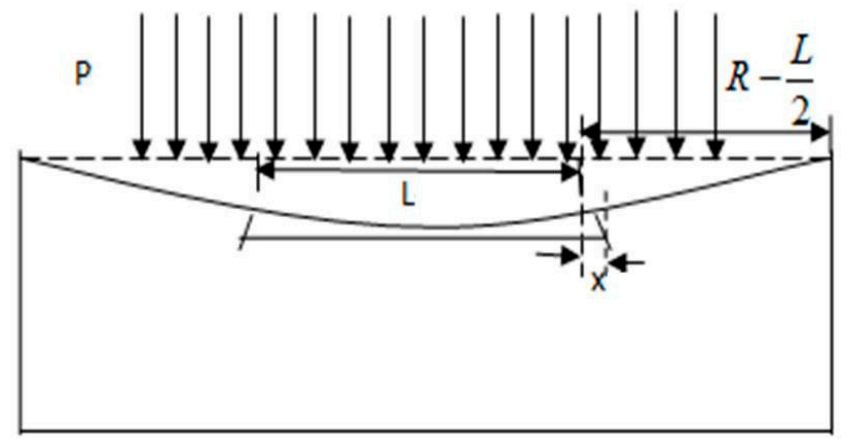

Figure 11. Force diagram of simplified model of flat diaphragm.

In Figure 11, $\mathrm{L}$ is the distance between fixed fiber columns, and $R$ is the radius of elastic diaphragm. It is known that the distance between the fixed columns $L=40 \mathrm{~mm}$, the height of the fixed column $m=10 \mathrm{~mm}$, and the radius of the diaphragm is $R=120 \mathrm{~mm}$. As shown in Figure 11, concave deformation of the compressed diaphragm occurs after compression, and then the deformation deflection of the diaphragm at the fixed column is $\omega^{\prime}=\frac{\omega}{R}\left(R-\frac{L}{2}\right)$.

Through calculation, the strain variable of the grating is shown in Equation (7).

$$
\varepsilon=\frac{2 m \operatorname{Sin}\left(\tan ^{-1} \frac{\omega}{R}\right)}{\mathrm{L}} .
$$

Thus, the sensor sensitivity can be obtained as (8):

$$
k=\frac{3\left(1-P_{e}\right) m R^{3}\left(1-\mu^{2}\right)}{8 E h^{3} L} .
$$

The elastic modulus of 304 stainless steel $E=1.942 \mathrm{GPa}$, Poisson's ratio $\mu=0.28$, sensor radius $R=120 \mathrm{~mm}$, height $h=50 \mathrm{~mm}$, fixed column height $m=10 \mathrm{~mm}$, distance between fixed columns $L=40 \mathrm{~mm}$, effective optical fiber elasto-optic coefficient $P_{e}=0.21$ and other relevant values, substituted into Equation (8) and can get the answer: $k=$ $42.544 \mathrm{pm} / \mathrm{Mpa}$.

\section{Experimental Calibration Results and Analysis}

\subsection{Pressure Calibration}

The sensor must be calibrated before use. In order to reduce the influence of temperature on the change of grating center wavelength as much as possible, the oil pressure calibration experiment was carried out in the constant temperature laboratory of pressure Research Institute of Shanxi Institute of Metrology. In the experiment, the FBG pressure sensor designed and manufactured is loaded into the BHY-160B Piston manometer through 
a special fixture, and then the sensor is connected with the FBG demodulator (SM125 of MOI) and computer, as shown in Figure 12.

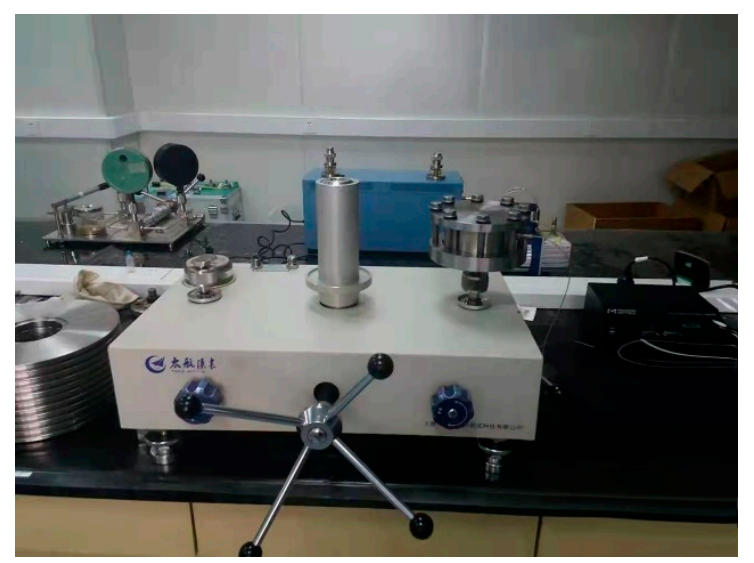

Figure 12. Oil pressure calibration experiment diagram.

The change of the central wavelength of the grating in the process of pressure and depressurization was observed by computer. The experiment adopts step-by-step pressurization, starting from $1 \mathrm{MPa}$, each time the pressurization range is $1 \mathrm{MPa}$, and then gradually increased to $50 \mathrm{MPa}$. In the step-down process, start from $50 \mathrm{Mpa}$ and step down $1 \mathrm{Mpa}$ each time until $0 \mathrm{Mpa}$. A round trip of pressurization and depressurization is regarded as one cycle, and three cycles are carried out continuously. Take the average output value of each pressure point as the measured value of that point. The collected data were analyzed according to the verification regulations of the pressure sensor, and the relationship between the output wavelength of the sensor, the pressure and the Error of detection was obtained, as shown in Figures 13 and 14: the pressure boost process was $\mathrm{y}=0.0406 \mathrm{x}+1544.7$, and $R^{2}=0.9921$. The depressurization process was $\mathrm{Y}=0.0435 \mathrm{x}+$ 1544.6, and $R^{2}=0.9985$.

It can be concluded that the fiber grating pressure sensor designed in this paper has good linearity and repetition performance of pressure calibration under constant temperature environment, and good experimental results have been obtained. According to the calculation, the pressure sensitivity of the sensor is $42.05 \mathrm{pm} / \mathrm{MPa}$, which is almost consistent with the theoretical calculation with a small deviation. The main reason is that the relevant material parameters in Equation (8), such as the effective elasto-optic coefficient, are those of ordinary quartz fiber, which is somewhat differ from the actual polyimide grating. Related indexes obtained after data processing. The repeatability is $0.066 \% \mathrm{FS}$; return error is $0.846 \% \mathrm{FS}$. Linear error is $0.102 \% \mathrm{FS}$. The accuracy is $\pm 0.591 \% \mathrm{FS}$.

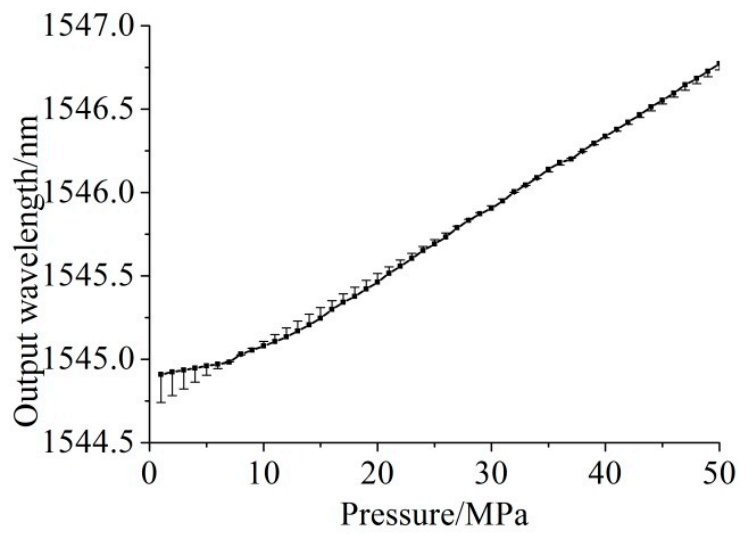

Figure 13. Compression calibration curve. 


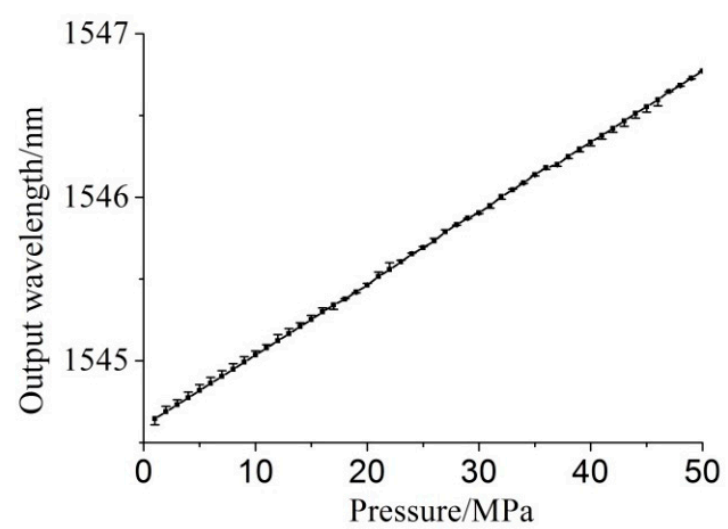

Figure 14. De-compression calibration curve.

\subsection{Temperature Calibration}

Put the sensor into the thermostat, and test the method of gradual heating of the sensor, starting from $100{ }^{\circ} \mathrm{C}$, each temperature rise is $20^{\circ} \mathrm{C}$, and then gradually increase the temperature to $300{ }^{\circ} \mathrm{C}$. Then, the sensor is cooled. In the cooling process, it starts from $300{ }^{\circ} \mathrm{C}$ and drops $20^{\circ} \mathrm{C}$ each time until $100{ }^{\circ} \mathrm{C}$. After holding for $4 \mathrm{~h}$ at each temperature point, the output of the pressure-sensitive grating FBG1 and the temperature-compensated grating FBG2 of the sensor were recorded every $10 \mathrm{~s}$, and the average value was taken as the output value of the point after 15 times of recording. The above experiment cycle was carried out three times. Grating output data were recorded and temperature-output wavelength diagrams were drawn, as shown in Figures 15 and 16.

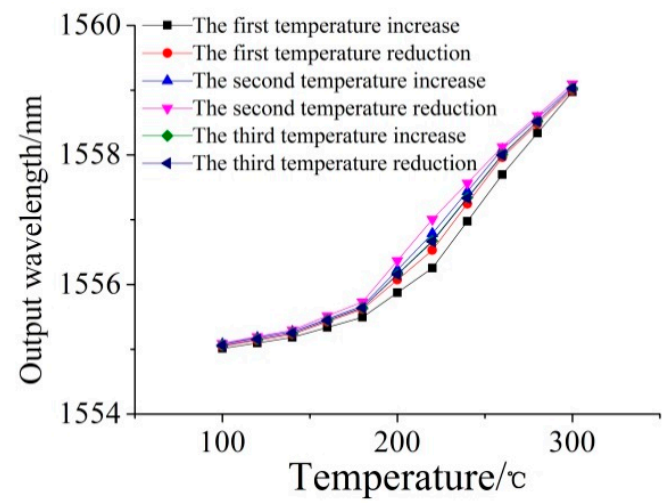

Figure 15. Temperature experimental data graph of pressure sensitive grating.

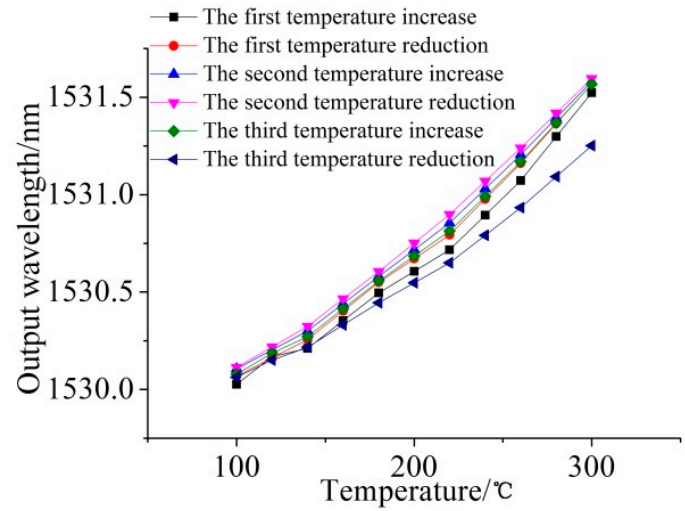

Figure 16. Temperature experimental data graph of temperature compensated grating.

From Figures 15 and 16, it can be seen that, due to the large detection range of temperature, the relationship between the output wavelength of grating and temperature 
is not linear. It is more reasonable to use the quadratic function to fit. The output of each temperature point was averaged as the verification indicator value for data analysis and processing, and the correlation coefficient $\mathrm{ABC}$ of the temperature response of sensor pressure-sensitive grating FBG1 and temperature-compensated grating FBG2 could be obtained. After calculation, the relationship between the output wavelength of pressure-sensitive grating and temperature is $\lambda=0.000092 t^{2}-0.015781 t+1555.670001$, $R^{2}=0.993529$, and the same relationship of the temperature compensated grating FBG is: $\lambda=0.000014 t^{2}+0.001607 t+1529.781912, R^{2}=0.99479$.

\subsection{High Temperature Pressure Calibration Experiment}

The pressure sensitivity of the FBG pressure sensor is directly related to the parameters such as the diameter of the sensor, the thickness of the film, the elastic modulus of the packaging material of the sensor and the Poisson's ratio. In high temperature environments, the elastic modulus of packaging material will decrease with the increase of temperature, so the sensitivity of the sensor will increase with the increase of temperature. In order to study the change trend of pressure sensitivity of FBG pressure sensor at different temperatures, and to master the pressure detection characteristics of the sensor in high temperature environment, pressure calibration experiments were carried out on the designed sensor at different temperatures.

In order to further study the pressure sensing characteristics of the sensor at high temperatures, the pressure and depressurization experiments at different temperatures were carried out. The sensor is put into a special airtight container, and the airtight container is connected with the air pressure pump through the rubber pipe. Put the closed container into the temperature test chamber, and the connection mode of the experimental device is shown in Figure 17. The measured video of the experiment is in the supporting file. At the same time, a high-precision thermocouple temperature tester (YET-610 T) is placed in the thermostat to calibrate the temperature of the thermostat.

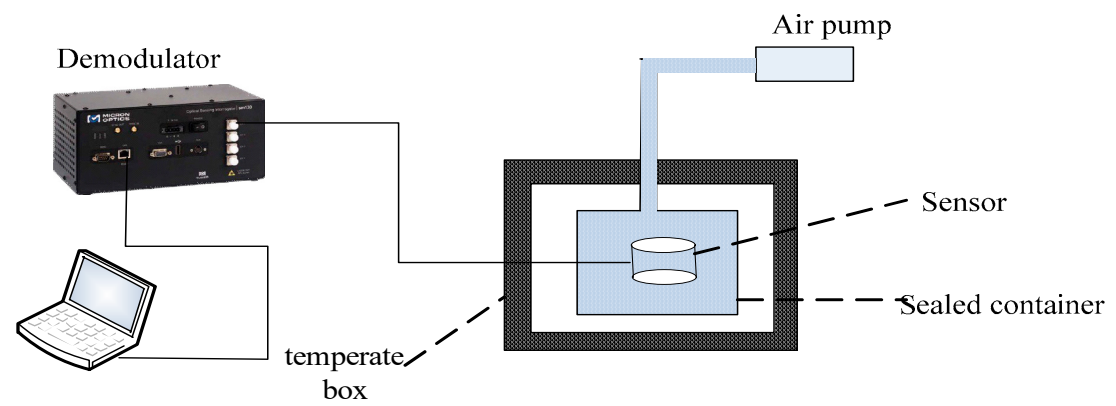

Figure 17. Schematic diagram of high temperature pressure calibration experiment device.

The thermostat was set from $100^{\circ} \mathrm{C}$ to $250{ }^{\circ} \mathrm{C}$ at an interval of $25^{\circ} \mathrm{C}$. After holding for $4 \mathrm{~h}$ at each temperature point to ensure that the output of the pressure-sensitive grating and the temperature complement grating were stable, the pressure and pressure reduction experiments were carried out on the sensor through a pneumatic pump. Starting from $0 \mathrm{MPa}$, the step length of $1.5 \mathrm{MPa}$ is gradually increased to $30 \mathrm{MPa}$, and then the step length of $1.5 \mathrm{MPa}$ is gradually decreased to $0 \mathrm{MPa}$. This cycle was repeated three times to record the output wavelength of the pressure-sensitive grating at different pressures at each temperature point for data processing, as shown in Figure 18. On this basis, the pressure sensitivity of the FBG sensor is calculated at each experimental temperature, and the curve is shown in Figure 19. As can be seen from Figure 19, the pressure sensitivity of the sensor increases with the increase of the ambient temperature detected, but its changing trend presents a nonlinear change. 


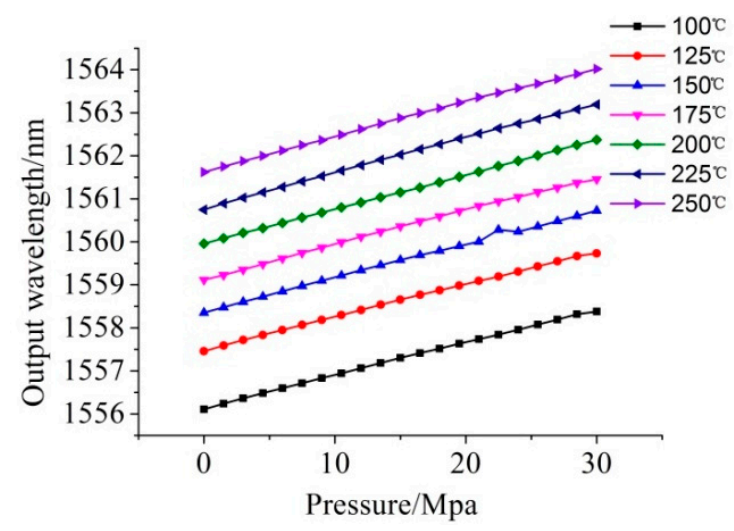

Figure 18. Pressure curve of different temperatures.

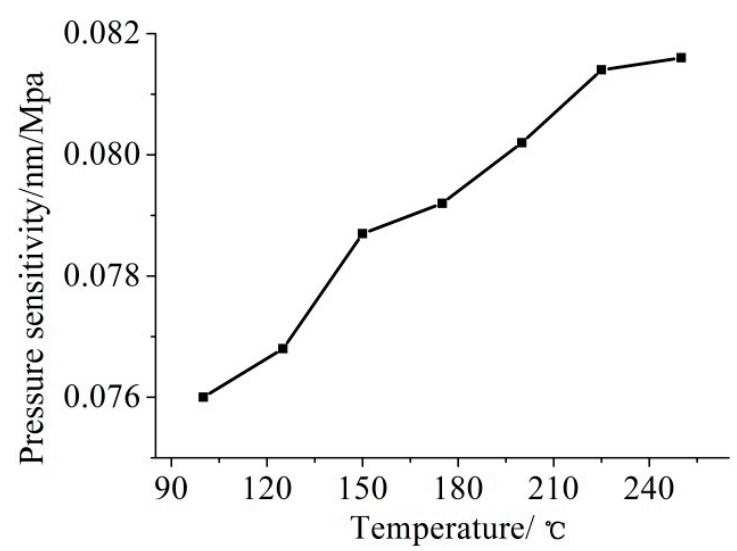

Figure 19. Summary sheet of pressure sensitivity of different temperatures.

In the high-temperature pressure calibration experiment, the pressure sensitivity of the designed sensor also shows a nonlinear change trend with the change of temperature. This is because the material parameters such as the elastic modulus and expansion coefficient of the packaging material change nonlinearly with temperature.

Due to the limitations of the equipment, the temperature can only be increased to $250{ }^{\circ} \mathrm{C}$, and it can only be pressurized to $30 \mathrm{MPa}$ in a high temperature environment. The parameters of the sensor vary at different temperatures. According to the pressure measurement data, at $250{ }^{\circ} \mathrm{C}$, the relevant indexes obtained after calculation and processing are as follows. The repeatability is $0.097 \%$ FS; Returned error is $0.966 \%$ FS. The linear error is $0.173 \%$ FS. The sensor accuracy is \pm 0.872 FS.

\subsection{Optimization of Temperature Compensation Effect}

The grating is cross-sensitive to temperature and strain. When the temperature changes, the wavelength of the grating changes with it. This will lead to an increase in the error of the pressure measurement value, so it is necessary to compensate the temperature of the grating sensor to minimize the influence of temperature changes and reduce the error of the pressure measurement value.

In order to realize the temperature compensation of the sensor, two gratings are arranged inside the sensor, one of which is pressure sensitive grating FBG1 and the other is temperature compensation grating FBG2. The two ends of pressure-sensitive grating FBG1 are bonded to two fixed columns, which are affected by temperature and strain at the same time. One end of the temperature compensated grating FBG2 is a free end, which is arranged on the member without force. It is only affected by temperature and is used to measure the temperature of the object being measured. Two gratings in the same temperature field have the same temperature effect. The influence of temperature and 
strain on the central wavelength of the fiber grating is independent, and the wavelength change of FBG1 can be expressed by Formula (9):

$$
\Delta \lambda_{1}=K_{P} \Delta P+A_{1} \Delta T^{2}+B_{1} \Delta T+C_{1},
$$

where, $K_{P}$ is the pressure sensitivity coefficient of FBG1 (nm/MPa); $A_{1}, B_{1}, C_{1}$ is the temperature sensitivity coefficient of FBG1; $\Delta T$ is the temperature change; $\Delta P$ is the pressure to be measured.

For the temperature-compensated grating FBG2, it is only affected by temperature. In this test environment, its wavelength changes as (10):

$$
\Delta \lambda_{2}=A_{2} \Delta T^{2}+B_{2} \Delta T+C_{2} .
$$

Although the two gratings are made of the same material, FBG1 is affected by the thermal expansion of the packaging material, so their temperature sensitivity is different. Therefore, it is necessary to calculate their temperature sensitivity coefficient $A B C$ respectively through temperature calibration experiment.

The experimental temperature can be calculated by Formula (10). Since the two fiber gratings are in the same temperature field, $\Delta T_{1}=\Delta T_{2}$.

By substituting the calculated temperature into Formula (9), the pressure $P$ to be measured can be obtained.

$$
P=\frac{\Delta \lambda_{1}-\left(A_{1} \Delta T^{2}+B_{1} \Delta T+C_{1}\right)}{K_{P}} .
$$

The $K_{P}$ is not a constant value. It is necessary to substitute the detected wavelength of the temperature-compensating grating into Formula (10) and the calculated the experimental temperature $\Delta T$. Then it can get the pressure sensitivity of the grating sensor $K_{P}$ from Figure 19, at that temperature. Finally, the pressure to be measured would be obtained by substituting $\Delta T$ and $K_{P}$ into Formula (11).

According to Formula (11), the larger the value of the temperature sensitivity coefficient is, the higher the temperature measurement accuracy of the temperature compensation grating is, the more accurate the temperature change value obtained thus, and the higher the calculation accuracy of the temperature compensation is. Therefore, for the temperature compensation grating, it is proposed to use the capillary copper tube with a large linear expansion coefficient to sensitize the package. When the temperature changes, the axial expansion of brass drives the synchronous expansion of the grating encapsulated in it. It will increase the temperature sensitivity coefficient.

In order to improve the temperature sensitivity of the temperature compensated grating and adjust the position of the temperature compensated grating, the structure of the sensor was optimized to achieve the same ambient temperature of the two gratings. A fixed column was added inside the sensor. The position of the fixed column was taken in the same straight line with the center of the pressure-sensitive grating along the $Y$-axis, and the height was the same as that of the fixed column of the pressure-sensitive grating. A brass capillary was welded on the top of the added fixed column, and the temperature compensation grating was inserted into the capillary and the two ends of the temperature compensation grating were fixed with the capillary to complete the sensitization package of the temperature compensation grating. The internal structure of the sensor after adjustment is shown in Figure 20. 


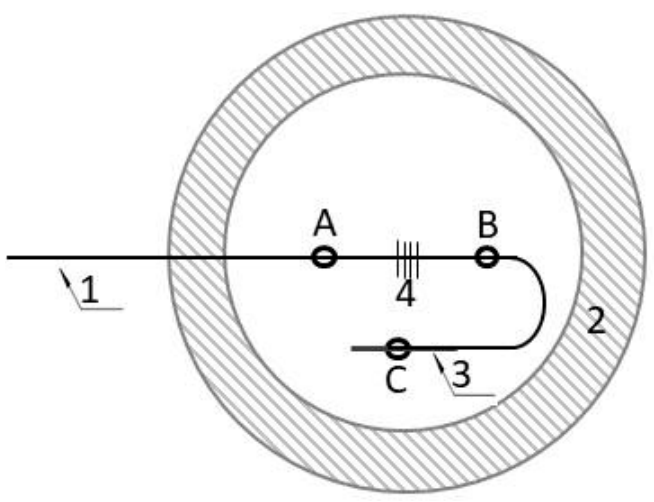

Figure 20. Optimized internal structure of the sensor. (1) Optical fiber (2) Sensor housing (3) Copper capillary (4) Pressure sensitive grating (A,B,C). Fixed column

As can be seen in Figure 20, the sensor is composed of stainless steel shell, optical fiber, pressure-sensitive grating, temperature compensating grating, three fixed column $A B C$ and copper capillary. Among the three fixed columns $A B C, A B$ is used to fix the pressure-sensitive grating, and the additional fixed column $C$ is used to fix the copper capillary that encapsulates the temperature-compensated grating. As can be seen from Figure 18, through structural adjustment, the two gratings are at the same height and the same longitudinal coordinate, which not only ensures that the two gratings are strictly in the same temperature field, but also realizes the sensitization package of the temperaturecompensated gratings. In addition, this structure can keep the temperature-compensated grating from straining when the sensor is subjected to an external force. It does not affect the pressure conversion mechanism of the sensor. The temperature experiment of the modified sensor was conducted again. The temperature sensitivity of the temperature compensating grating is three times higher than that of the grating before packaging, which can improve the temperature compensation effect of the pressure measuring grating. Comparison of error curves before and after structural adjustment is shown in Figure 21.

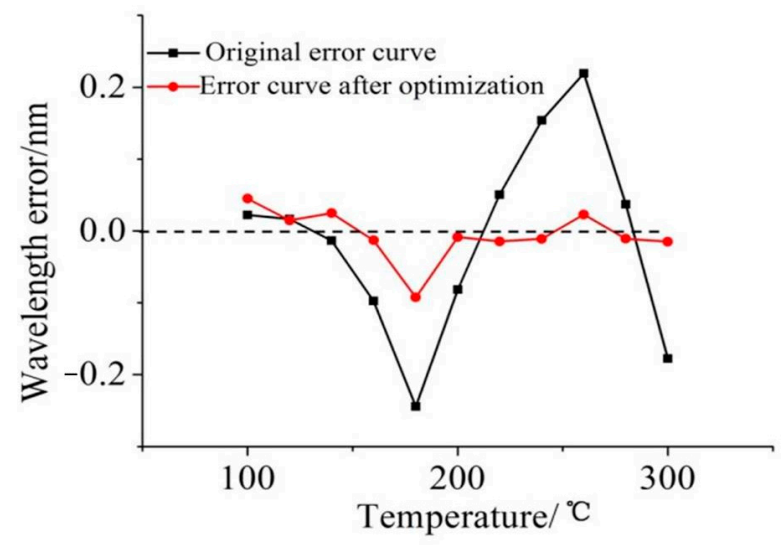

Figure 21. Comparison of temperature compensation effect.

The dotted line in Figure 21 is the ideal location for temperature compensation. The closer it is to the dotted line, the better the temperature compensation effect will be. It can be seen from Figure 21 that the red point is significantly closer to the dotted line than the black point, indicating that the optimized structure has achieved better temperature compensation effect.

\section{Conclusions}

The following conclusions can be drawn from the study: 
1. Pressure and temperature calibration experiments indicate that the FBG based pressure sensor has good linearity and the pressure sensitivity is $42.05 \mathrm{pm} / \mathrm{MPa}(\leq 50 \mathrm{MPa})$ at room temperature;

2. Temperature compensation method is proposed based on temperature calibration experiment. The pressure measurement error of the sensor at the different temperatures without loading condition has been conducted to optimize the sensor structure. It further realizes the strict synchronization of the temperature field between the temperature-compensating FBG and the FBG for pressure measurement. The study improves the accuracy of temperature measurement and the temperature compensation;

3. The pressure calibration experiments in the range of $100{ }^{\circ} \mathrm{C} 250{ }^{\circ} \mathrm{C}$ verifies the accuracy of pressure measurement at high temperature and provides the pressure sensitivity at different temperatures.

The sensor can be used to monitor the pressure of explosive in weapon warhead, the activity of volcano, the high pressure in various inflammable and explosive, electromagnetic interference, strong radiation and high-temperature environments.

Author Contributions: For research articles, H.G. was responsible for sensor design, structure simulation, experimental calibration and paper writing; J.C. tooe charge of paper modification and proofreading; Z.T. was responsible for experimental calibration and data processing; A.W. was charge of graphic modification. All authors have read and agreed to the published version of the manuscript.

Funding: This work was supported by National Natural Science Foundation of China (51509174); Teaching Reform Project of Shanxi Province(J2020282); Applied Basic Research Project of Xinzhou Science and Technology Bureau(20200110); Scientific research fund of Xinzhou teachers university(2019KY04).

Institutional Review Board Statement: Not applicable.

Informed Consent Statement: Not applicable.

Data Availability Statement: The data used to support the findings of this study are available from the corresponding author upon request.

Acknowledgments: In this section, we would like to acknowledge Modern Testing and Information Processing Laboratory, college of Information and Communication Engineering, North University of China, and the Pressure Measurement Institute of Shanxi Academy of Metrology for their assistance in the high pressure calibration process of the sensor.

Conflicts of Interest: The authors declare no conflict of interest.

\section{References}

1. Lee, B. Review of the present status of optical fiber sensors. Opt. Fiber Technol. 2003, 9, 57-79. [CrossRef]

2. Liao, Y.; Ecke, W.; Schmitt, M.W.; Shieh, Y.; Lindner, E.; Willsch, R.; Jin, W.; Sampson, D.D.; Yamauchi, R.; Chung, Y.; et al. Continuous pressure and temperature monitoring in fast rotating paper machine rolls using optical FBG sensor technology. In Proceedings of the OFS2012 22nd International Conference on Optical Fiber Sensors, Beijing, China, 14-19 October 2012; p. 8421AZ.

3. Fu, T.; Gong, Y.; Wu, Y.; Ma, Y.-Y.; Niu, W.-Q. Performance evaluation of temperature-compensated FBG pressure sensor. In Proceedings of the ISPDI 2013-Fifth International Symposium on Photoelectronic Detection and Imaging, SPIE, Beijing, China, 25-27 June 2013; p. 89140M.

4. Witzigmann, B.; Guo, Z.; Liu, G.; Meng, Q.; Ge, F.; Li, W.; Osinski, M.; Henneberger, F.; Arakawa, Y. FBG pressure sensor of high pressure electric oil pumps for prestressing. In Physics and Simulation of Optoelectronic Devices XXI; International Society for Optics and Photonics: Tanjing, China, 2013.

5. Hao, J.-C.; Leng, J.-S.; Wei, Z. Non-destructive Evaluation of Composite Pressure Vessel by Using FBG Sensors. Chin. J. Aeronaut. 2007, 20, 120-123. [CrossRef]

6. He, S.; Hu, S.; Tian, D.; Yu, K.; Zhao, Q.; Zhou, J.; Wang, L. A novel FBG pressure sensor with high sensitivity. Photonics Asia 2005, 5633, 299-302. [CrossRef]

7. Shao, T.; Wu, J.; Zhang, Y.; Cheng, Y.; Zuo, Z.; Lv, H.; Ying, M.; Wong, C.P.; Li, Z. Highly Sensitive Conformal Pressure Sensing Coatings Based on Thermally Expandable Microspheres. Adv. Mater. Technol. 2020, 5, 5. [CrossRef] 
8. Vohra, S.T. High sensitivity pressure sensors utilizing advanced polymer coatings. In Proceedings of the 13th International Conference on Optical Fiber Sensors, SPIE, Kyongju, Korea, 12-16 April 1999; p. 99.

9. Wang, M.; Wang, D.; Yang, M.; Cheng, J.; Li, J. In-line Mach-Zehnder Interferometer and FBG with Pd film for simultaneous hydrogen and temperature detection. Sens. Actuators B Chem. 2014, 202, 893-896. [CrossRef]

10. Sun, A.; Qiao, X.G.; Jia, Z.A.; Li, M.; Zhao, D.Z. Study of simultaneous measurement of temperature and pressure using double fiber Bragg gratings with polymer package. Opt. Eng. 2005, 44, 034402. [CrossRef]

11. Ahmad, H.; Harun, S.W.; Chong, W.Y.; Zulkifli, M.Z.; Thant, M.M.M.; Yusof, Z.; Poopalan, P. High-sensitivity pressure sensor using a polymer-embedded FBG. Microw. Opt. Technol. Lett. 2008, 50, 60-61. [CrossRef]

12. Zou, J.; Song, D.; Wei, Z.; Yang, S.; Cui, H.-L. High-sensitivity fiber Bragg grating pressure sensor using metal bellows. Opt. Eng. 2009, 48, 034403. [CrossRef]

13. Xiong, Y.; He, J.; Yang, W.; Sheng, L.; Gao, W.; Chen, Y. Research on FBG Pressure Sensor of Flat Diaphragm Structure. In Proceedings of the International Conference on Measurement, Information and Control (MIC), Harbin, China, 18-20 May 2012; pp. 787-790.

14. Li, F.; Du, Y.; Zhang, W.; Li, F. Fiber Bragg grating soil-pressure sensor based on dual L-shaped levers. Opt. Eng. 2013, 52, 014403. [CrossRef]

15. Huang, J.; Zhou, Z.; Wen, X.; Zhang, D. A diaphragm-type fiber Bragg grating pressure sensor with temperature compensation. Measurement 2013, 46, 1041-1046. [CrossRef]

16. Pachava, V.R.; Kamineni, S.; Madhuvarasu, S.S.; Putha, K. A high sensitive FBG pressure sensor using thin metal diaphragm. J. Opt. 2014, 43, 117-121. [CrossRef]

17. Pachava, V.R.; Kamineni, S.; Madhuvarasu, S.S.; Mamidi, V.R. Fiber Bragg grating-based hydraulic pressure sensor with enhanced resolution. Opt. Eng. 2015, 54, 96104. [CrossRef]

18. Pachava, V.R.; Kamineni, S.; Madhuvarasu, S.S.; Putha, K.; Mamidi, V.R. FBG based high sensitive pressure sensor and its low-cost interrogation system with enhanced resolution. Photonic Sens. 2015, 5, 321-329. [CrossRef]

19. Allwood, G.; Wild, G.; Lubansky, A.; Hinckley, S. A highly sensitive fiber Bragg grating diaphragm pressure transducer. Opt. Fiber Technol. 2015, 25, 25-32. [CrossRef]

20. Dolan, D.H. Accuracy and precision in photonic Doppler velocimetry. Rev. Sci. Instrum. 2010, 81, 053905. [CrossRef] [PubMed]

21. Li, T.; Tan, Y.; Zhou, Z.; Zheng, K. A non-contact FBG vibration sensor with double differential temperature compensation. Opt. Rev. 2016, 23, 26-32. [CrossRef]

22. Ko, P.-L.; Chuang, K.-C.; Ma, C.-C. A Fiber Bragg Grating-Based Thin-Film Sensor for Measuring Dynamic Water Pressure. IEEE Sens. J. 2018, 18, 7383-7391. [CrossRef]

23. Mathew, J.; Havermann, D.; Polyzos, D.; MacPherson, W.; Hand, D.P.; Maier, R.R.J. SS316 structure fabricated by selective laser melting and integrated with strain isolated optical fiber high temperature sensor. In Proceedings of the 24th International Conference on Optical Fibre Sensors, SPIE, Curitiba, Brazil, 28 September-2 October 2015; p. 96340Q.

24. Wang H P, Chen H: The Structural Performance of CFRP Composite Plates Assembled with Fiber Bragg Grating Sensors. Symmetry 2021, 13, 1631. [CrossRef]

25. Wang, H.P.; Dai, J.G. Improved temperature compensation of fiber Bragg grating-based sensors applied to structures under different loading conditions. Opt. Fiber Technol. 2021, 63, 102506. [CrossRef]

26. Guo, H.-Y. Research on Solid Pressure Sensor for High-pressure Measurement Based on Fiber Bragg Grating. Chin. J. Anal. Chem. 2017, 45, 980-986.

27. Guo, H.-Y.; Wang, Z.-B.; Li, H.-Y. Development and Commissioning of High Temperature FBG Solid Pressure Sensors. J. Sens. 2018, 2018, 1-8. [CrossRef]

28. Warren-Smith, S.C.; Nguyen, L.V.; Ebendorff-Heidepriem, H.; Monro, T.M. High temperature sensing with single material silica optical fibers. In Proceedings of the 25th International Conference of Optical Fiber Sensors, Jeju, Korea, 24-28 April 2017; pp. 10323-10324.

29. Butov, O.V.; Golant, K.M.; Grifer, V.I.; Gusev, Y.V.; Kholodkov, A.V.; Lanin, A.V.; Maksutov, R.A.; Orlov, G.I. Versatile in-Fiber Bragg Grating Pressure Sensor for Oil and Gas Industry. Available online: https: / / www.osapublishing.org/abstract.cfm?uri= OFS-2006-TuB6 (accessed on 10 September 2021).

30. Butov, O.V.; Golant, K.M.; Nikolin, I. Ultra-thermo-resistant Bragg gratings written in nitrogen-doped silica fibres. Electron. Lett. 2002, 38, 523-525. [CrossRef]

31. Shen, J.; Li, T.; Zhu, H.; Yang, C.; Zhang, K. Sensing Properties of Fused Silica Single-Mode Optical Fibers Based on PPP-BOTDA in High-Temperature Fields. Sensors 2019, 19, 5021. [CrossRef] [PubMed] 